\title{
The chlamydial functional homolog of KsgA confers kasugamycin sensitivity to Chlamydia trachomatis and impacts bacterial fitness Rachel Binet ${ }^{* 1,2}$ and Anthony T Maurelli ${ }^{1}$
}

Address: ${ }^{1}$ Department of Microbiology and Immunology, F. Edward Hébert School of Medicine, Uniformed Services University of the Health Sciences, 4301 Jones Bridge Road, Bethesda, MD 20814-4799, USA and ${ }^{2}$ Current address: U.S. Food and Drug Administration, Office of Regulatory Science, 5100 Paint Branch Pkwy, College Park, MD 20740, USA

Email: Rachel Binet* - rbinet@usuhs.mil; Anthony T Maurelli - amaurelli@usuhs.mil

* Corresponding author

Published: 31 December 2009

BMC Microbiology 2009, 9:279

10.1 186/147|-2180-9-279
Received: 30 June 2009

Accepted: 31 December 2009

This article is available from: http://www.biomedcentral.com/147I-2180/9/279

(C) 2009 Binet and Maurelli; licensee BioMed Central Ltd.

This is an Open Access article distributed under the terms of the Creative Commons Attribution License (http://creativecommons.org/licenses/by/2.0), which permits unrestricted use, distribution, and reproduction in any medium, provided the original work is properly cited.

\begin{abstract}
Background: rRNA adenine dimethyltransferases, represented by the Escherichia coli KsgA protein, are highly conserved phylogenetically and are generally not essential for growth. They are responsible for the post-transcriptional transfer of two methyl groups to two universally conserved adenosines located near the 3 'end of the small subunit rRNA and participate in ribosome maturation. All sequenced genomes of Chlamydia reveal a ksgA homolog in each species, including C. trachomatis. Yet absence of a S-adenosyl-methionine synthetase in Chlamydia, the conserved enzyme involved in the synthesis of the methyl donor S-adenosyl-L-methionine, raises a doubt concerning the activity of the KsgA homolog in these organisms.
\end{abstract}

Results: Lack of the dimethylated adenosines following ksgA inactivation confers resistance to kasugamycin (KSM) in E. coli. Expression of the C. trachomatis L2 KsgA ortholog restored KSM sensitivity to the $E$. coli ksgA mutant, suggesting that the chlamydial KsgA homolog has specific rRNA dimethylase activity. C. trachomatis growth was sensitive to KSM and we were able to isolate a KSM resistant mutant of $C$. trachomatis containing a frameshift mutation in $k s g A$, which led to the formation of a shorter protein with no activity. Growth of the $C$. trachomatis ksgA mutant was negatively affected in cell culture highlighting the importance of the methylase in the development of these obligate intracellular and as yet genetically intractable pathogens.

Conclusion: The presence of a functional rRNA dimethylase enzyme belonging to the KsgA family in Chlamydia presents an excellent chemotherapeutic target with real potential. It also confirms the existence of S-adenosyl-methionine - dependent methylation reactions in Chlamydia raising the question of how these organisms acquire this cofactor.

\section{Background}

Ribosomes are complex macromolecular machines that are found in abundance in all cells that are actively making proteins. Two-thirds of the ribosome is composed of RNA molecules (rRNA) that share a high degree of conservation in primary sequence as well as in secondary and tertiary structural elements across kingdoms [1]. Numerous nucleotide modifications, mainly but not exclusively via methylation, are found on rRNAs but the functional importance of these post-transcriptional modifications remains unclear [2]. For example, the two adenosine residues in the loop of helix 45 near the 3 'end of the small 
subunit rRNA (positions 1518 and 1519 of the 16S rRNA in the Escherichia coli numbering system) are universally conserved, and are dimethylated by a specific enzyme belonging to the rRNA adenine dimethylase family, which is represented by the E. coli KsgA protein [3]. While these enzymes are present in all three kingdoms of life including mitochondria and chloroplasts [4], a few KsgA orthologs adopted additional roles within the cell, serving for example as a transcription factor in mitochondria [5] or an essential ribosome biogenesis factor in yeast [6]. However, dimethylation is generally not essential for growth at optimal temperature.

The order Chlamydiales forms a deep lineage of obligate intracellular bacteria, infecting free-living amoebae, various invertebrates and all the vertebrates, and includes four families: Chlamydiaceae, Parachlamydiaceae, Waddliaceae, and Simkaniaceae [7]. The Chlamydiaceae are well known agents of multiple diseases in animals and in humans, with two species, C. trachomatis and C. pneumoniae, being pathogenic for humans. C. trachomatis is recognized as the most prevalent cause of bacterial sexually transmitted infections worldwide and, in underdeveloped nations, is also responsible for trachoma a potentially blinding disease. C. pneumoniae is a significant agent of respiratory disease in adolescents and adults and also is associated with cardiovascular diseases. The other chlamydial species are less relevant to human medicine, although severe zoonotic diseases in humans are caused by C. psittaci, $C$. abortus and C. felis. Species of Parachlamydiaceae, Waddliaceae, and Simkaniaceae are also suspected to be involved in human infections [8].

In addition to being obligate intracellular Gram-negative bacteria, all chlamydiales share a unique biphasic developmental cycle. The environmentally stable, metabolically inert and infectious elementary bodies (EBs) enter susceptible host cells and convert into the replicating and metabolically active but noninfectious reticulate bodies (RBs) inside cytoplasmic vacuoles (also called inclusions) before converting back into EBs from 18 to 48 hours postinfection depending on the species, and exiting the host cell to repeat the cycle [9]. While effective antibiotic therapies are available to treat chlamydial infections, it is becoming clear that the low number of rRNA operons in these bacteria presents an actual risk for emergence of resistance against the current preferred therapies of tetracycline or azithromycin $[10,11]$. Then, similar to other bacteria, targets for the development of new antimicrobials need to be identified.

The evolution of Chlamydia as an obligate intracellular pathogen has been associated with loss of genes encoding functions that became redundant within the host during the adaptation to parasitic/symbiotic lifestyles, similarly to mycoplasmas, phytoplasmas, $\alpha$ - and $\gamma$-proteobacteria [12]. Sequencing data available for eleven Chlamydia species reveal the presence of a KsgA dimethyltransferase homolog, yet they all lack the S-adenosyl-methionine synthetase that is required for synthesis of S-adenosylmethionine, the donor of methyl groups in all methylation reactions. This raises the question of whether the $\mathrm{ksgA}$ homolog encodes a functional methylase in these organisms. The lack of tools for genetically manipulating Chlamydia has been a major barrier to the analysis of their putative virulence genes [13] and characterization of chlamydial genes has mainly relied on expression in a heterologous host system such as E. coli. In this study, we show that the chlamydial KsgA protein is able to functionally replace the orthologous enzyme in $E$. coli, indicating that they share the same activity, i.e. specific methylation of the small subunit ribosomal RNA. KsgA activity conferred sensitivity to the antibiotic kasugamycin (KSM) in Chlamydia, similarily to E. coli, and we were able to isolate low level $\mathrm{KSM}^{\mathrm{R}}$ mutants in C. trachomatis which contain a frameshift mutation in $k s g A$. These mutant bacteria were severely impaired for growth, highlighting the critical role KsgA plays in Chlamydia biology.

\section{Results and discussion I-Characterization of the chlamydial KsgA orthologs and their phylogenetic relationship with other family members} A gene encoding a protein highly similar to the dimethyltransferase KsgA is present in the genomes of all sequenced Chlamydia. Using degenerate primers, we were amplified a $5 \mathrm{~kb}$-genomic region of $C$. psittaci 6BC carrying the $\mathrm{ksgA}$-like gene. $\mathrm{ksgA}$ is the second gene of a predicted bicistronic operon in Chlamydia [14], downstream of a gene, named ct355 in C. trachomatis serovar D, with no homology outside the chlamydiae lineage. CT355 ORF shows 59 to $100 \%$ homology amongst the Chlamydiacee and $26 \%$ with the protochlamydial pc0396 ORF which precedes the protochlamydial ksgA gene.

Genomic transcriptional profiling of $C$. trachomatis serovar D showed that both ksgA and ct355 genes are transcribed by 8 hours post-infection when the bacteria are in the metabolically active stage of development [15]. Surprisingly, while most $k s g A$ orthologs use the AUG canonical translation initiation codon, an alternative $k s g A$ start codon is predicted amongst the Chlamydiaceae, either GUG in C. trachomatis, C. muridarum and C. pneumoniae or UUG in C. psittaci 6BC, C. felis, C. caviae and C. abortus. While use of an alternative start codon usually results in low expression in E. coli, its impact on efficiency of translation in Chlamydia is not known. Nevertheless like E. coli, most chlamydial genes rely on AUG as a start codon [16].

A multiway alignment between various KsgA homologs revealed 62 to $68 \%$ identity amongst the Chlamydiaceae 
and at least 99\% within each species, 39\% with the protochlamydial homolog, 25 to 30\% with Arabidaposis thaliana, Synechococcus sp., Prochlorococcus sp., E. coli, Rickettsia sp. and Yersinia sp. KsgA orthologs, and 20\% with the mitochondrial transcriptional factor h-mtTFB1 (data not shown). Using a refined sequence alignment, a phylogenetic tree was constructed for these various dimethyltransferases [17] (see Materials and Methods). The branches representing Chlamydia were similar whether nucleotide sequences (data not shown) or protein sequences (Figure 1) were aligned. They were both comparable to the one obtained using 16S rRNA and 23S rRNA gene sequences [18] or housekeeping gene fragments [19], except that $C$. pneumoniae was slightly more distant in our analysis, with a strong branch support value of $86 \%$.

The chlamydial KsgA homologs, in particular the protochlamydial one, grouped with the A. thaliania chloroplastic PFC1 (Paleface1) protein, in agreement with two recent studies [4,20] (Figure 1). Although the evolutionary relationship between plants and Chlamydia may seem surprising considering that no species of Chlamydia has been
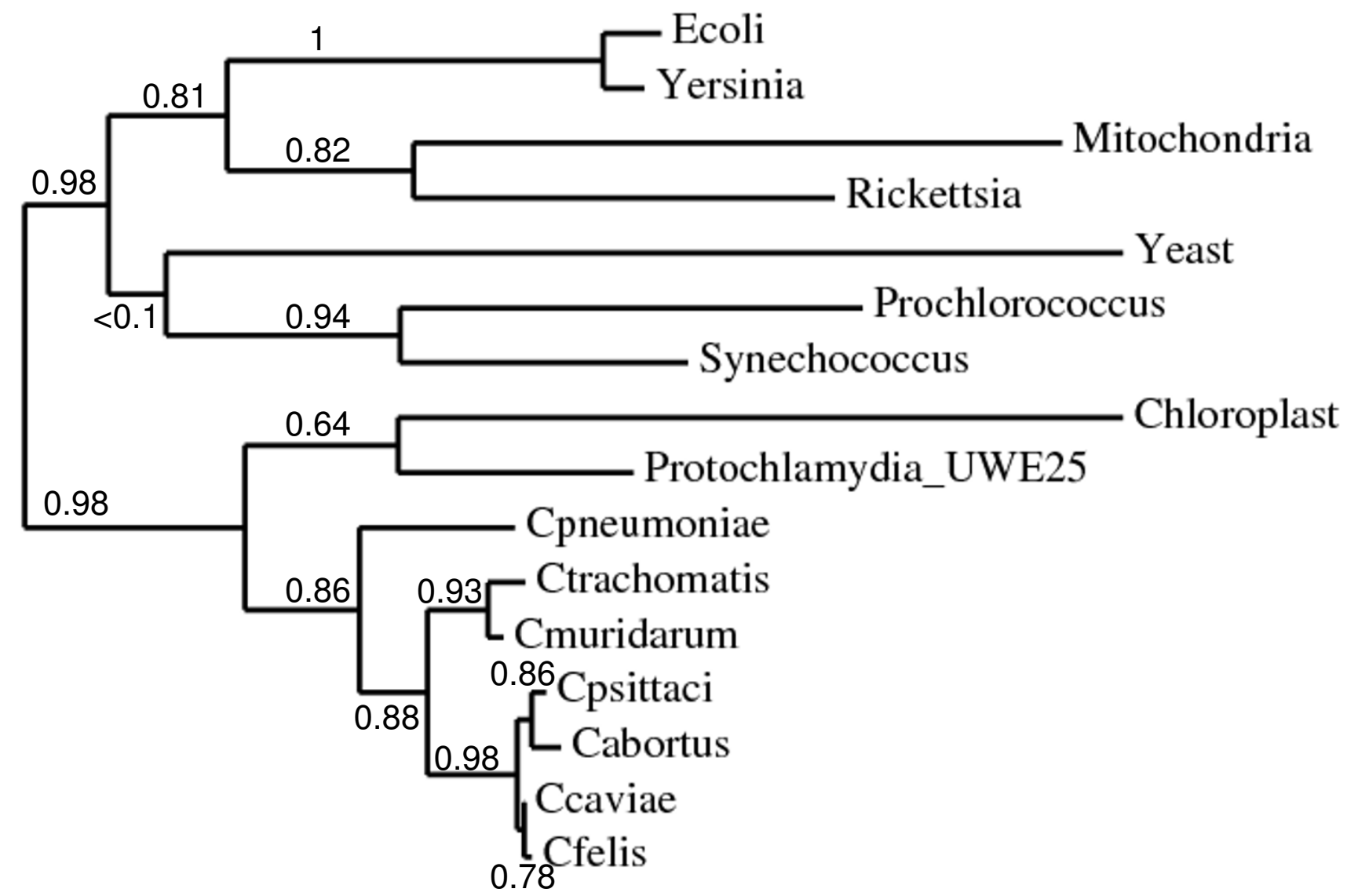

\section{5}

Figure I

Phylogenetic analysis of protein sequences showing the relationship between various KsgA orthologs. Sequences were aligned and analyzed on the phylogeny.fr interface. Due to the conservation of KsgA sequences, only one representative of each chlamydial species was chosen for clarity of the tree. GenBank accession no.: NP_4I4593 (Escherichia coli KI2),

YP_069175 (Yersinia pseudotuberculosis), NP_057I04 (transcription factor BI, mitochondrial [Homo sapiens]), CAA72482 (Rickettsia prowazekii), P4I8I9 (Dim Ip, Saccharomyces cerevisiae), YP_001017626 (Prochlorococcus marinus str. MIT 9303), YP_001734I57 (Synechococcus sp. PCC 7002), NP_I7I690 (PFC-I, chloroplastic, Arabidopsis thaliana), YP_007394 (Candidatus Protochlamydia amoebophila UWE25), NP_445330 (C. pneumoniae AR39), YP_001654684 (C. trachomatis serovar L2), NP_297007 (C. muridarum Nigg ), GQ28473I (C. psittaci 6BC), CAH63750 (C. abortus S26/3), NP_829I74 (C. caviae GPIC ), YP_5I56I7 (C. felis Fe/C-56) 
reported in photosynthetic organisms, a high number of cyanobacteria- and plant-like genes in Chlamydia have been identified in the different chlamydial genome sequences $[21,22]$. Further analyses showed that many of the plant orthologs are targeted to the plastids in plants. We recently demonstrated that $C$. trachomatis L2 and $P$. amoebophila DapL enzymes behave similarly to the phylogenetically related plant plastidial LL-diaminopimelate aminotransferase enzyme involved in the lysine biosynthetic pathway [23]. Accordingly, we predict that the chlamydial KsgA proteins should be functionally equiva- lent to the plastid orthologs. In addition, conservation of hallmark sequences for binding to the methyl group donor S-adenosyl-L-methionine and to the adenine ring of the nucleotide to be methylated (Figure 2) predict that the chlamydial KsgA proteins should complement a KsgA defect in E. coli, as seen previously with KsgA family members [5,24-27].

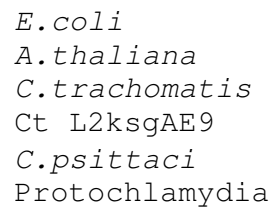

\section{E.COIi}

A. thaliana

C.trachomatis

Ct L2ksgAE9

C.psittaci

Protochlamydia

\author{
E.COIi \\ A. thaliana \\ C.trachomatis \\ CtL2ksgAE 9 \\ C.psittaci \\ Protochlamydia
}

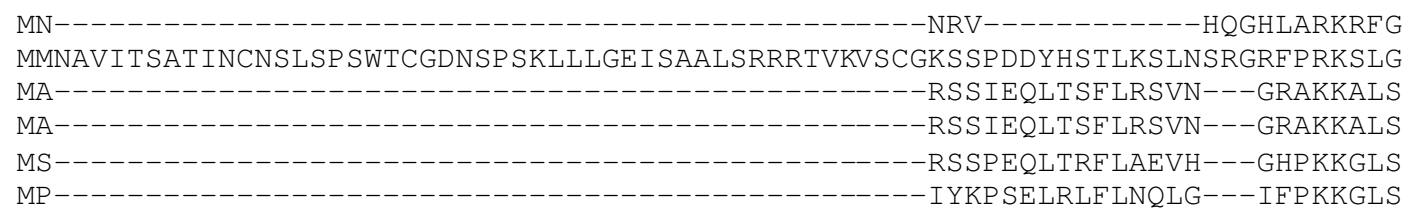

QNF LNDQFVIDSIVSAINPQKGQAMVEIGPGLAALTEPVGERLDQLTVIELDRDLAARLQTHPFLGPKLTIYQQDAM QHYMLNSD IND QLASAADVKEGDFVLEIGP GTGS LTNVLINLGATVLAIEKDP HMVDLVSERFAGSDKFKVLQEDFV QNF LVDGNI LRKILTTAEVQP GDWVLEI GP GF GALSEVLLSQGANV IALEKDPMFEES LSQLPM-----DIEITDAC QNF LVDGNI LRK I LTTAEVQP GDWVLEIGP GF GALSEVLLSQGANVIALEKDPMFEES LSQLPM-----DIEITDAC QNF LIDGNI LRKILAVSCVQAGDWVLEIGP GFGALTEVLVNQGAHVVALEKDPMFEETLKQLPI-----HLEITDAC QNF LIDGNI IRK IVRASDVQP GNLVLEIGP GP GS LTQAMLEVEAHVVAVEKDFVLARELKRFQTP SKQLEIFCEDIL

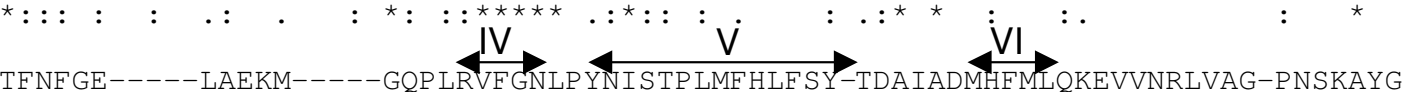
KCH IRS HMLS ILETRRLSHPD SALAKVVSNLP FNI STDVVKLLLP-MGD IF SKVVLLLQDEAALRLVEPALRTSEYR KYPLTS-----LEDKGW----KGKGRIVANLPYH ITTP LLTKFF LECPYRWKTVTVMIQDEVARRITAK-P GDKDYG KYPLTS-----LEDKGW----KGKGRIVANLPYHITTP LLTKFF LECPYRWKTVTVMIQDEVARRITAK-PGDKDYG KYP LSQ-----LQDKGW----QGKGRVVANLPYHVTTP LLTKLF LEVPNQWKTVTVMIQDEVARRIKAQ-PGGKEYG MF SVEE----ELQSRLR---DDQKAKVIANLPYHLTTP I LAEMVVR-RKLF SS LTVMVQEEVARRMTAL-PGQSDYS

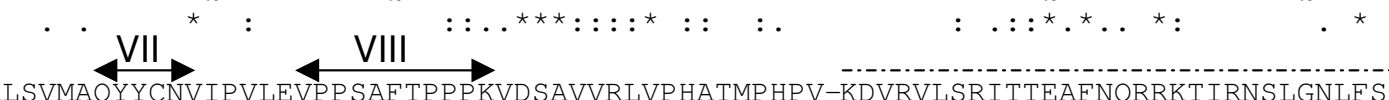
RLSVMAQYYCNVIPVLEVPPSAFTPPPKVDSAVVRLVP HATMP HPV-KDVRVLSRITTEAFNQRRKTIRNSLGNLFS P INILINFYSEPEYNFRVPRENFFPQPKVDAAVVTFKLKHP RDYPDVSSTKNFF SLVNSAFNGKRKMLRKSLQHISS SLTVFLSFFADVQYAFKVSPNCFYPKP SVHSAVVHMRVHEQFALAD-SEIEEFFTLTRAAFGQRRKLLANSLKNLYP SLTVFLSFFADVQYAFKVSPNCFYPKPSVCTRLL- SLTIFLQFFVDVRYAFKVSP GCF LPKPQVSSAVVHMTVKDRFPLEE-P LRTKFF SLTRAAFGQRRKLLANALKDLYP SFTIFLNFYSKPRYGF TVSRNCFYPAPKVDSAIVVLELKEP--PPN-IDAQVFFKITRTAFEQRRKMLRASLKSLFD

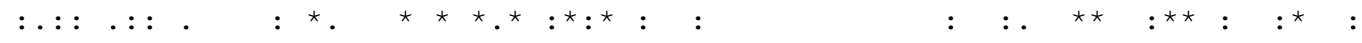
V---EVLTGMGIDPAMRAENISVAQYCQMANYLAENAP LQES SPDIEKALGVAGLPATSRPEELTLDDFVKLHNVIA------RE KDKVFQVLEQLGF SEKTRPETIFLEEYLKIFHLLK------DI ------------------- SICEFTSSLHWLI ------ LK KERVFEALSQLNF SDKTRPETLSLDDYLKLFELLS-----LHA PSKISNALEI IGQNPQARPEVLSLEDF IKLYHELYS---SERH $:{ }^{\star} \quad{ }^{*}{ }^{\star}::::::$ : $:$

\section{Figure 2}

Structure-based sequence alignment of the KsgA alleles from E. coli (NP_414593), A. thaliana (NP_I 1690 i.e. PFCI), C. trachomatis L2 (YP_00I654684 i.e. CTL0608), C. trachomatis L2ksgAE9, C. psittaci 6BC (GQ28473I) and Candidatus Protochlamydia amoebophila UWE25 (YP_007394 i.e. pc0395). The alignment was generated using the Tcoffee expresso Web server using the structure of $E$. coli KsgA (PDB ID IQRYR). Identical residues are denoted with an asterisk and strongly conserved residues with a colon; weakly conserved residues are marked with a period. Double-headed arrows indicate structural or catalytic motifs (I to VIII) common to S-adenosylmethionine-dependant methyltransferases and a dotted line indicates the C-terminal domain of $E$. coli KsgA [49]. Shading shows change in amino acid sequence in KsgA $\mathrm{L}_{\mathrm{L} \text { ksgaEg }}$ resulting from frameship up to stop codon and truncation. 


\section{2-Complementation of a ksgA mutant of $\mathrm{E}$. coli by the chlamydial ksgA homologs}

E. coli are naturally sensitive to KSM, an aminoglycoside antibiotic that inhibits the initial step of protein synthesis. Sensitivity to KSM is in part due to the action of KsgA which methylates the adenosine residues at positions 1518 and 1519 of the 16S rRNA. [Note that we use the $E$. coli numbering system throughout when referring to nucleotide(s) in rRNA genes]. Consequently, ksgA mutants are resistant to KSM [28]. We constructed a clean deletion of $k s g A$ in E. coli MC4100 (Table 1) using the $\lambda$ red recombinase method as described by Datensko and Wanner [29]. This strain, ATM809, was 16 times more resistant to KSM than the wild-type strain, with a minimal inhibitory concentration (MIC) of $2500 \mu \mathrm{g} \mathrm{ml}^{-1} \mathrm{vs.} 150 \mu \mathrm{g}$ $\mathrm{ml}^{-1}$ for its parent (Table 1 ). The ability of $E$. coli and $C$. trachomatis L2 ksgA genes to complement the KSM resistance phenotype and restore KSM sensitivity to ATM809 was first tested by transforming high copy number plasmids (Table 1) and expressing the respective genes in the presence of $1 \mathrm{mM}$ Isopropyl $\beta$-D-1-thiogalactopyranoside (IPTG). Colonies formed by ATM809 transformed with pRAK316 (i.e. overexpressing C. trachomatis L2 KsgA protein, designated $\mathrm{KsgA}_{\mathrm{L} 2}$ for simplicity) were about $50 \%$ smaller than ATM809 or ATM809 transformed with pRAK297 (i.e. overexpressing the E. coli protein) (p < 0.0001 by t-test). The inhibition of growth due to overexpression of $\mathrm{KsgA}_{\mathrm{L} 2}$ made it impractical to assess sensitivity to KSM. To address this problem we constructed isogenic strains of ATM809 in which the copy number of the IPTGinducible $k s g A$ gene was reduced by inserting it into the chromosome at the $\lambda$-attachment site (Material and Methods). Under such conditions, we did not observe any growth inhibition associated with $\mathrm{KsgA}_{\mathrm{L} 2}$ expression in the absence of antibiotic ( $\mathrm{p}>0.1$ by t-test).

Expression of the native E. coli methylase in the E. coli ksgA mutant (i.e. ATM810) restored sensitivity to KSM as expected (Figure 3), with a MIC of $150 \mu \mathrm{g} \mathrm{ml}^{-1}$ (Table 1). Similarly, expression of $\mathrm{KsgA}_{\mathrm{L} 2}$ was able to complement for the loss of $k s g A$ in E. coli (Figure 3). As expected, the level of bacterial sensitivity to KSM was inversely related to the expected expression level of the recombinant protein in E. coli, lowering the MIC from 800 to $400 \mu \mathrm{g} \mathrm{ml}^{-1}$ when the $k s g A_{L 2}$ GUG native start codon was replaced by the conventional AUG start codon to increase the level of expression of $\mathrm{KsgA}_{\mathrm{L} 2}$ (Table 1). Likewise expression of the C. psittaci 6BC KsgA ortholog restored KSM sensitivity to the E. coli ksgA mutant (Table 1). The restoration of KSM sensitivity supports the conclusion that the chlamydial KsgA homologs are able to methylate the two conserved adenosines at positions 1518 and 1519 in E. coli $16 \mathrm{~S}$ rRNA in vivo, as has been seen previously for different KsgA family members from mitochondria, bacteria and yeasts $[24,25,27,30,31]$.

The importance of KsgA in ribosome maturation has been linked to the cold-sensitivity phenotype described for $E$. coli $k s g A$ mutants and $A$. thaliana $p f_{c} 1$ mutants $[32,33]$. Nevertheless expression of $\mathrm{KsgA}_{\mathrm{L} 2}$ in ATM809 did not reverse the cold-sensitivity growth of the E. coli strain (Figure 4). We do not know if this reflects a functional dispar-

Table I: Bacterial strains used in this study and MICs for KSM

\begin{tabular}{|c|c|c|c|}
\hline Strains & Description & Source or reference & KSM MIC ( $\left.\mu \mathrm{g} \mathrm{ml}^{-1}\right)$ \\
\hline \multicolumn{4}{|l|}{ E. coli } \\
\hline $\mathrm{DH} 5 \alpha$ & $\begin{array}{l}\mathrm{F}-\varphi 80 \Delta(\text { lacZY-argF)Ul69 deoR recAI endAI phoA hsdRI } 7 \text { supE44 } \lambda \text { - thi-I gyrA96 } \\
\text { relAI } \Delta(\text { lacZ)MI5 }\end{array}$ & {$[56]$} & NT \\
\hline BW25II3 & $\Delta(a r a D-a r a B) 567 \Delta l a c Z 4787$ (::rrnB-3) $\lambda-r p h-I \Delta(r h a D-r h a B) 568$ hsdR5 /4 & [29] & NT \\
\hline MC4I00 & F- araDI39 $\Delta$ (argF-lac)UI69 rpsLI50 relAI deoCI rbsR fthD530I fruA25 $\lambda$ - & {$[57]$} & 150 \\
\hline \multirow[t]{3}{*}{ ATM809 } & MC4I00 $\Delta$ ksgA::cat & This work & 2500 \\
\hline & ATM809 transformed with pRAK297 [Plac::E. coli ksgA in pGEMT] & This work & 200 \\
\hline & $\begin{array}{l}\text { ATM809 transformed with pRAK325 [Plac:: C. psittaci 6BC UUG-ksgA in } \\
\text { PGEMT] }\end{array}$ & This work & 1000 \\
\hline ATM8I0 & ATM809 att:: E.coli ksgA & This work & 200 \\
\hline ATM8I 2 & ATM809 att:: C.trachomatis GUG-ksgA & This work & 800 \\
\hline ATM8II & ATM809 att:: C.trachomatis AUG-ksgA & This work & 400 \\
\hline ATM8I5 & ATM809 att:: C.trachomatis AUG-ksgAE9 & This work & 2500 \\
\hline C. psittaci 6BC & strain 6BC & T. Hatch & 1100 \\
\hline $\mathrm{BCK}_{1}$ & $\begin{array}{l}\text { Spontaneous } \mathrm{Ksm}^{\mathrm{R}} \text { variant of } \mathrm{C} \text {. psittaci } 6 \mathrm{BC} \text { with } \mathrm{A}_{794} \mathrm{G} \text { mutation in the } 16 \mathrm{~S} \\
\text { rRNA gene }\end{array}$ & {$[13]$} & $>>5000$ \\
\hline C. trachomatis $\mathrm{L} 2$ & biovar lymphogranuloma venereum L2/434/Bu & H. Caldwell & 800 \\
\hline L2 ksgAE9 & C. trachomatis L2 ksgAE9 & This work & 3000 \\
\hline
\end{tabular}

NT; Not Tested 


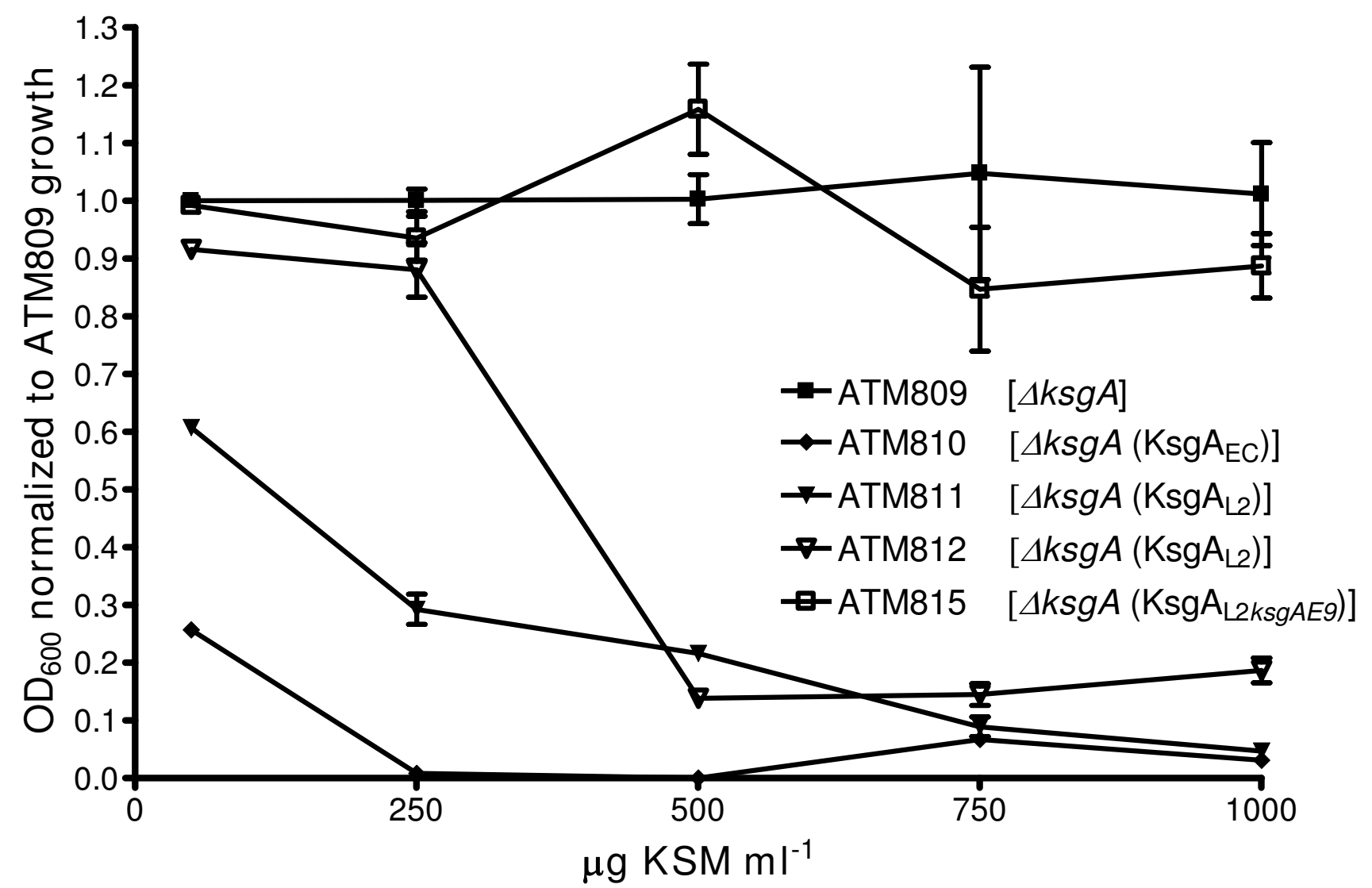

Figure 3

KSM inhibition growth of E. coli ATM809 derivatives. A ksgA mutant of E. coli (i.e. ATM809) harboring a chromosomal copy of ksgA from E. coli (ATM8I0), C. trachomatis L2 (ATM8I I, ATM8I2) or the KSM resistant C. trachomatis L2ksgA

(ATM8I5) were tested for resistance to KSM as described in [30], with some modifications. The $A_{600}$ of cultures after 24 hrs of growth in the presence of the indicated amounts of KSM was normalized to the value obtained for ATM809 under the same conditions. Data points represent the mean \pm s.d. of three experiments. The parent MC4I00 behaved like ATM8I0 and was not included for clarity.

ity of the chlamydial KsgA homolog or just results from partial heterologous complementation suggested by the intermediate level of KSM sensitivity exhibited by the $k s g A_{L 2}$-complemented $E$. coli mutants. Nevertheless, the ability of $\mathrm{KsgA}_{\mathrm{L} 2}$ to restore some degree of sensitivity towards KSM, hence methylation of $\mathrm{A}_{1518}$ and $\mathrm{A}_{1519}$ in $E$. coli $16 \mathrm{~S}$ rRNA, suggests that the same conserved adenosine residues are methylated in Chlamydia [3,6,33-36]. Consequently, we explored Chlamydia sensitivity to KSM.

\section{3-Inhibition of C. trachomatis L2 and C. psittaci 6BC growth by KSM and selection of resistant mutants}

Although KSM has been used clinically in the treatment of Pseudomonas aeruginosa infections [37], this aminoglycoside antibiotic is only currently used in agricultural protection of rice crops against the fungus Pyricularia oryzae. Genetic, biochemical, and structural analyses have provided insights into KSM binding and inhibition [38-42].
The drug binds to the 30 S ribosomal subunits within the path of the messenger RNA (mRNA), overlapping both the peptidyl-tRNA (P) and exit (E) sites. This affects the binding of the initiator tRNA onto canonical mRNAs and the subsequent joining of the large 50S subunits to form the translationally active $70 \mathrm{~S}$ ribosomes. KSM is held in place by interactions with universally conserved residues $\mathrm{A}_{794}$ and $\mathrm{G}_{926}$ on the $16 \mathrm{~S}$ rRNA and although the antibiotic does not appear to interact directly with the two adenosines at positions 1518 and 1519, lack of methylation in $\mathrm{A}_{1519}$ decreases KSM binding to rRNA. $[39,40]$. The conservation of these nucleotides in Chlamydia predicts that these obligate intracellular bacteria should be sensitive to KSM, provided that both the cell and the inclusion membrane are permeable to the drug.

In our laboratory, sensitivity of Chlamydia spp. to antibiotics is measured in the plaque assay and the MIC is 


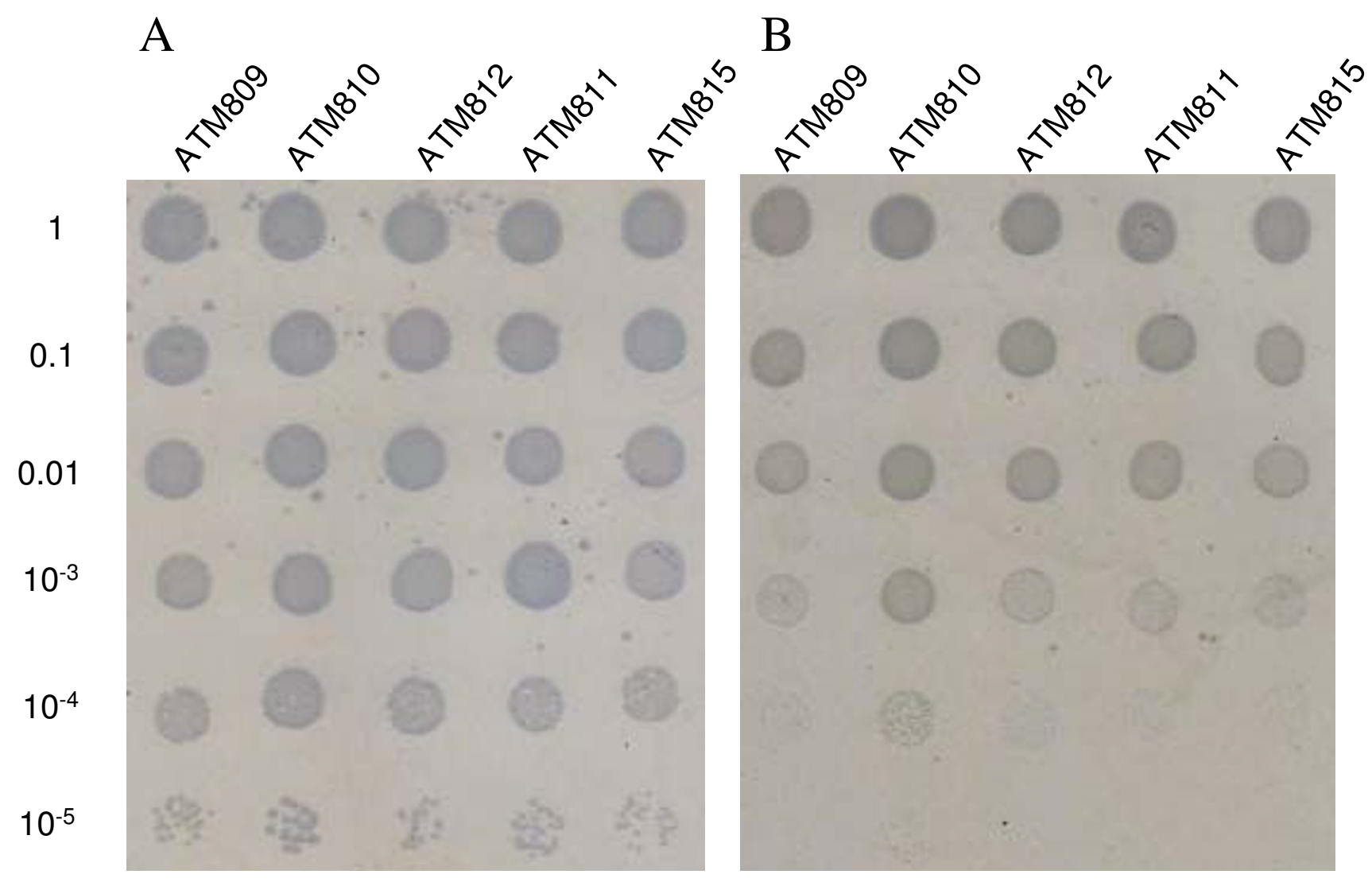

Figure 4

Growth efficiency of various E. coli ATM809 derivatives at $30^{\circ} \mathrm{C}$ (panel A) and $20^{\circ} \mathrm{C}$ (panel B). Exponential cultures diluted in 10 -fold increments were spotted on LB supplemented with IPTG and incubated at $30^{\circ} \mathrm{C}$ for 12 hrs and $20^{\circ} \mathrm{C}$ for 30 hrs.

defined as the concentration of drug that inhibits the development of $10^{5}$ plaque-forming units (PFU). The number of input bacteria corresponds to a multiplicity of infection (MOI) of 0.01 in a confluent monolayer of L2 mouse fibroblasts in $60 \mathrm{~mm}$ dishes $[10,11,13]$. Due to low intracellular penetration, aminoglycosides are considered poorly active or not active against obligate intracellular bacteria and indeed C. psittaci 6BC and C. trachomatis L2 MIC for KSM were high, i.e. 1100 and $800 \mu \mathrm{g} \mathrm{ml}{ }^{-1}$, respectively (Table 1). Although such elevated MICs would classify the organisms as KSM resistant from a clinical stand point, we hypothesized that alterations in the drug binding site, in the KsgA methylase or in the rRNA methylation site would allow Chlamydia to grow in the presence of even higher concentrations of KSM, as reported for other bacteria $[28,38,43,44]$.

When monolayers were infected with $10^{6}$ to $10^{7} \mathrm{PFU}$ in the presence of KSM at 2000, 3000 or $5000 \mathrm{\mu g} \mathrm{ml}^{-1}$, resistant plaques appeared at a frequency of $2.20 \pm 0.64 \times 10^{-5}$ for C. psittaci 6BC while no plaques were seen for C. trachomatis under the same conditions (frequency $<5.3 \times 10^{-}$ $\left.{ }^{8}\right)$. We have previously observed this difference in behavior between the two chlamydial strains for acquisition of resistance towards other ribosome targeting antibiotics $[10,11]$. Because expression of resistance requires that more than $50 \%$ of the ribosome population be of the resistant phenotype, $C$. trachomatis with two rRNA operons is at a disadvantage compared to $C$. psittaci 6BC which harbors only one rRNA operon. KSM started to affect $C$. trachomatis $\mathrm{L} 2$ growth at $100 \mu \mathrm{g} \mathrm{ml}-1$, but a concentration of $200 \mu \mathrm{g} \mathrm{ml}^{-1}$ was completely inhibitory when cells were infected with a few hundred PFUs. Therefore we reasoned that serial passage in subinhibitory concentrations of antibiotic would allow the enrichment of putative low level $\mathrm{KSM}^{\mathrm{R}}$ bacteria, as previously seen for azithromycin [10]. Three independent cultures of $C$. trachomatis L2 were passaged up to 14 times in KSM ranging from 100 to $800 \mu \mathrm{g}$ $\mathrm{ml}^{-1}$. Three individual clones were then selected and purified in the plaque assay using $300 \mu \mathrm{gSM} \mathrm{ml} \mathrm{KS}^{-1}$. 


\section{4-Molecular and phenotypic characterizations of KSM resistance mutations in $C$. psittaci $6 B C$ and $C$. trachomatis $L 2$}

Sixteen independent spontaneous $\mathrm{KSM}^{\mathrm{R}}$ plaques were isolated for C. psittaci 6BC, expanded twice in the presence of $2000 \mu \mathrm{g} \mathrm{KSM} \mathrm{ml}-1$ and further analyzed. DNA sequence analysis showed that none carried a mutation in $k s g A$. However, sequencing of the unique 16S rRNA gene revealed an A to $G$ mutation at position 794 which is known as one of the binding sites for $\operatorname{KSM}[39,40]$. Similarly, three C. trachomatis L2 isolates that arose in the presence of $300 \mu \mathrm{g} \mathrm{KSM} \mathrm{ml}{ }^{-1}$ were further expanded in the presence of the drug and analyzed. None carried a mutation in the drug binding sites as expected from the presence of two rRNA operons in the strain [45]. None carried a mutation in rpsI encoding the 30 S ribosomal subunit S9 protein that is a target for KSM resistance [46]. Sequencing of the $k s g A_{\mathrm{L} 2}$ DNA region revealed the insertion of a $t g$ nucleotide doublet in the last third of the gene. This doublet base-pair insertion, likely the result of a replication slippage [47], creates an early in-frame stop codon in the $k s g A$ coding sequence, resulting in the expression of a KsgA variant of 213 residues instead of 277 (Figure 2).

Stability of the acquired phenotype was then tested on one representative mutant of both classes (Table 1) by growth in the absence of selective pressure (i.e. no KSM). Plaques formed by the C. psittaci $6 \mathrm{BC} \mathrm{BCK}_{1}$ and the C. trachomatis L2 ksgAE9 variants grown for a minimum of 14 days in the absence of selection displayed the same number of infectious particles when titered in the presence or absence of 2000 and $200 \mu \mathrm{g} \mathrm{KSM} \mathrm{ml-1}$, respectively, indicating that the resistance phenotype was stable (data not shown). Growth of C. psittaci $\mathrm{BCK}_{1}$ was not

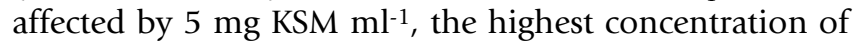
KSM that was not toxic to the mouse fibroblast cells. On the other hand, plaques formed by C. trachomatis ksgAE9 were already smaller in the presence of $200 \mu \mathrm{g} \mathrm{ml}^{-1} \mathrm{KSM}$, while $3 \mathrm{mg} \mathrm{ml}^{-1}$ of the drug inhibited at least $10^{5} \mathrm{ksgAE9}$ PFUs (i.e. MIC) (Table 1). The moderate level (i.e. less than 4-fold) of KSM resistance conferred by mutations in ksgA likely precluded C. psittaci 6BC ksgA mutants from being selected directly in the plaque assay $[10,11]$.

High level KSM resistance associated with mutations in the drug binding sites has only been observed previously in engineered strains of E. coli [38] and B. subtillis [44] in which each of the seven or ten rRNA operons, respectively, were inactivated, and the strains expressed only one rRNA operon encoded on a plasmid. Although both studies still reported that $k s g A$ mutations are the main mechanism of resistance to $\mathrm{KSM}$, mutations in the drug-binding site at position $A_{794}$ and $G_{926}$ of the $16 \mathrm{~S}$ rRNA conferred four to eight times more resistance to KSM than KsgA inactivation or alteration of the adenosine targeted by the methylase at position 1519 of the $16 \mathrm{~S}$ rRNA. In this study, all KSM ${ }^{\mathrm{R}}$ mutations selected in C. psittaci 6BC mapped to the drugbinding site at position $\mathrm{A}_{794} \mathrm{G}$. Our inability to isolate $\mathrm{KSM}^{\mathrm{R}}$ plaques for $C$. psittaci $6 \mathrm{BC}$ with mutations in the 16S rRNA gene at position 926 or 1519 suggests that either they do not confer KSM resistance levels high enough to be selected in the plaque assay or they impose a significant burden on bacterial fitness. Such species-specific bias for drug resistance mutations has been reported for other ribosome-targeting antibiotics including tetracycline, linezolid and macrolides [48].

\section{5-KsgA is critical for optimal growth of Chlamydia}

Serial passages in sub-inhibitory concentrations of KSM allowed the purification of a C. trachomatis variant synthesizing a shortened rRNA adenine dimethyltransferase enzyme in which the eight structural and catalytic methyltransferase motifs were maintained, but harboring 20 unrelated amino acids because of the frameshift at codon 203 (Figure 2). Overexpression of the truncated chlamydial protein in ATM809, the E. coli ksgA mutant, was strongly inhibitory for cell growth, as observed earlier with the wild-type $\mathrm{KsgA}_{\mathrm{L} 2}$ protein. On the other hand expression from a copy of $k s g A E 9$, the frameshift mutant, integrated in the bacterial chromosome, i.e. in ATM815, had no consequence on bacterial growth in the absence or in the presence of KSM (Figure 3), with a MIC of 2000 $\mu \mathrm{g} \cdot \mathrm{ml}^{-1}$ (Table 1 ). This shows that the chlamydial KsgA Cterminal tail is essential for activity in this heterologous system. Crystal structure analyses revealed that the N-terminal and the C-terminal portions of E. coli and Thermus thermophilus KsgA orthologs form two domains and the presence of several positively charged residues in the Cterminal domain predicted its involvement in binding to rRNA [31,49]. Recent evidence has shown that both domains interact with $16 \mathrm{~S}$ rRNA in $30 \mathrm{~S}$ ribosomal subunits [42]. More specifically the C-terminal domain of KsgA competes with the C-terminal domain of initiation factor IF3 for binding with the central domain of 16S rRNA. Accordingly, KsgA would prevent ribosomes that are undergoing methylation from entering the translational cycle [42]. As a result one might expect immature ribosomes to enter translation in cells that lack KsgA thus bearing a physiological cost.

Screening for KSM resistance in C. trachomatis allowed us to select for $k s g A$ mutations in these as yet genetically intractable pathogens [13]. Interestingly, plaques formed by the $C$. trachomatis L2 ksgAE9 variant in the absence of antibiotic were smaller than the wild-type strain $(\mathrm{p}<$ 0.0001 by t-test) with sizes of $0.27 \mathrm{~mm} \pm 0.11$ and 0.45 $\mathrm{mm} \pm 0.13$, respectively. This result shows that alteration in KsgA affects the fitness of $C$. trachomatis in vitro, similarly to Mycobacterium tuberculosis [50]. It is worth noting that although inactivation of $k s g A$ has a minimal effect on 
growth of E. coli or B. subtilis at $37^{\circ} \mathrm{C}$, recent studies have shown that the mutants are outcompeted by the wild-type strains at $37^{\circ} \mathrm{C}$ [44]. Similarly, while growth of a Y. pseudotuberculosis ksgA mutant is not severely affected under normal laboratory conditions, the mutant strain is attenuated in the mouse model indicating that dimethylation is essential for optimal fitness of the pathogen in vivo [51]. Although, the lack of a small animal model for C. trachomatis L2 precludes us from testing the consequences of KsgA inactivation on the pathogenicity of the strain, it is tempting to assume that the impairment of $C$. trachomatis L2 growth in vitro seen for our ksgA mutant would be reflected by an attenuation in virulence in vivo.

\section{Conclusions}

When high throughput screening of compounds predicted to bind to Bacillus subtillis RNA methyltransferase ErmC identified new compounds that were inhibitory to the growth of C. pneumoniae in vitro, Alvesalo et al. proposed that these small compounds were targeting the bacterial KsgA homolog [52]. Considering that ribosome biogenesis factors are emerging as potential therapeutic targets to combat pathogens [32], the present work provides evidence that Chlamydia possess a functional rRNA dimethylase enzyme that is important for optimal growth of these obligate intracellular organisms. The demonstration of two methyltransferases in Chlamydia ([53] and this study) raises the question of how these obligate intracellular bacteria obtain S-adenosyl-methionine to carry out these modifications. Our laboratory is currently investigating this aspect of Chlamydia biology.

\section{Methods}

\section{Bacterial strains and antibiotics}

The bacterial strains used in this study are listed in Table 1. Escherichia coli strain DH5 $\alpha$ was used for cloning purposes. E. coli strains were grown in Luria-Bertani (LB) broth with aeration or on LB agar. Ampicillin (Sigma) was used at $100 \mu \mathrm{g} \mathrm{ml}^{-1}$ to maintain plasmids in E. coli and at $25 \mu \mathrm{g} \mathrm{ml}^{-1}$ to select for the ATM809 derivatives harboring a single copy of the pGEMT-insert integrated in the chromosome (Table 1). KSM (Biomol) was used at the concentrations indicated.

\section{Propagation of Chlamydia and tissue culture cells}

C. trachomatis serovar L2/LGV/434/Bu and C. psittaci serovar $6 \mathrm{BC}$ were grown in mouse fibroblast L2 cells as previously described [11].

\section{Nucleic acid manipulation and sequence data analysis}

Total genomic DNA was prepared from C. trachomatis L2 or C. psittaci 6BC infected cells with DNeasy Tissue Kits (Qiagen). To identify the ksgA genomic region in C. psittaci $6 \mathrm{BC}$, a $5.6 \mathrm{~kb}$ product was amplified by PCR using degenerate primers designed from highly conserved genes surrounding the ksgA chromosomal region in the Chlamydiaceae (i.e. UpK-F1 [5'-CGACCACTCTGCCACTCTTCC$\left.3^{\prime}\right]$ and DWK-R1 [5'-CCYGTRATYTTWGCKATAGATCGTCGAGG-3']). The PCR product was cloned into pGEMT (Promega) and sequenced by the Biomedical Instrumentation Center at USUHS. Nucleotide sequences and predicted protein sequences were analyzed and aligned using Clone Manager 8 (Scientific \& Educational Software, Durham, NC), focusing mainly on ksgA and its upstream gene, i.e. CT354 and CT355 respectively (C. trachomatis serovar D designation, GenBank accession number NC000117). Protein homolog searches used the bioinformatic tools provided by the National Center for Biotechnology Information (NCBI) and by the Berkeley Phylogenomics group http://phylogenomics.berke ley.edu/tools.php.

KsgA phylogenetic analysis was performed on the Phylogeny.fr platform [17] and comprised the following steps. Sequences were aligned with MUSCLE (v3.7) configured for highest accuracy (MUSCLE with default settings). After alignment, ambiguous regions (i.e. containing gaps and/ or poorly aligned) were removed with Gblocks (v0.91b) using the following parameters: -minimum length of a block after gap cleaning: 10; -no gap positions were allowed in the final alignment; -all segments with contiguous non conserved positions bigger than 8 were rejected; -minimum number of sequences for a flank position: $85 \%$. The phylogenetic tree was reconstructed using the maximum likelihood method implemented in the PhyML program (v3.0 aLRT). The WAG substitution model was selected assuming an estimated proportion of invariant sites (of 0.055) and 4 gamma-distributed rate categories to account for rate heterogeneity across sites. The gamma shape parameter was estimated directly from the data (gamma=1.612). Reliability for internal branch was assessed using the aLRT test (SH-Like). Graphical representation and edition of the phylogenetic tree were performed with TreeDyn (v198.3).

\section{Construction of the E. coli KI2 $\triangle \mathrm{ksgA}$ mutant, ATM809}

An $E$. coli $k s g A$-mutant was generated first in strain BW25113 (Table 1) using the $\lambda$ Red recombinase method described by Datensko and Wanner [29]. The pKD4 template plasmid (chloramphenicol resistance) was used with the primers KD5 [5'CACCCAATGAATAATCGAGTCCACCAGGGCCACTTAG CCCGTAAACGCtgtgtaggctggagctgcttc-3'] and KD6 [5'CGAATTGATCATCGTTAACTCTCCTGCAAAGGCGCGTT CTCCGCCAcatatgaatatcctccttagttcc-3']. The PCR product that contains 46 bp of DNA homologous to the E. coli chromosomal regions flanking $k s g A$, shown underlined in the above primers, was used to electroporate BW25113 containing the $\lambda$ Red recombinase expression plasmid pKD46. Expression of the $\lambda$ Red system allowed for 
recombination of the PCR product into the bacterial chromosome and replacement of the chromosomal ksgA copy by the chloramphenicol resistance gene. This mutation was confirmed using PCR analysis of genomic DNA using the primers ksgA-F3 [5'-ACCCAATGAATAATCGAGTCCACC-3'] and ksgA-R2 [5'-TGATCATCGTTAACTCTCCTGCAAAG-3']. Next, a P1L4 lysate was grown on the $\triangle k s g A:: c a t$ strain and used to transduce MC4100 to chloramphenicol resistance, creating ATM809 (Table 1). Deletion of $k s g A$ in ATM809 was confirmed by PCR analysis (see above) and resulted in increased resistance to KSM (Table 1).

\section{Cloning of ksgA in plasmid pGEMT}

Complementation plasmids were constructed by cloning PCR products generated from E. coli or chlamydial DNA lysates into pGEMT (Promega), under the control of the lactose promoter. Sequencing of all cloned genes was performed by the Biomedical Instrumentation Center at USUHS. E. coli $\mathrm{K} 12 \mathrm{ksgA}$ gene was amplified using primers ksgA-F3 and ksgA-R2, creating pRAK297. C. trachomatis L2 ksgA gene was amplified using primers DWK-R2 [5'-ACTCAAGATCTCTAATCATAATCCCA-3'] and ksgA-F [5'AGGGTGGCACGGAGTTCTATAGAAC-3'] containing the genuine GUG start codon or ksgAF5 [5'-GGATGGCACGGAGTTCTATAGAAC-3'] where the GUG start codon has been replaced by the conventional AUG start codon, creating pRAK317 and pRAK316, respectively. pRAK363 was constructed similarly to pRAK316 except that the PCR product was amplified from C. trachomatis L2 ksgAE9 genomic DNA (Table 1). C. psittaci 6BC ksgA homolog was amplified using primers ksgA-F8 [5'-CGCTATGGCTTTGACTCATCG-3'] and ksgA-R6 [5'-CACTTAGGCGTGCAATGAGAG-3'] and cloned in pGEMT under the control of the lactose promoter, creating pRAK325. In this construct the putative $\mathrm{KsgA}_{6 \mathrm{BC}}$ UUG start codon was $\sim 60$ bp downstream of the Ribosome Binding Site, and was consequently expected to be expressed at a low level in $E$. coli due to polar effect. Accordingly, unlike E. coli transformants harboring pRAK316, pRAK317 or pRAK363, we did not observe any growth defect in E. coli pRAK325 transformants after addition of IPTG (see below).

\section{Insertion of the ksgA-pGEMT inserts into ATM809 chromosome}

We predicted that expressing $\mathrm{KsgA}_{\mathrm{L} 2}$ at a physiological level will reduce the growth inhibition observed in $E$. coli when the gene was carried on high copy vectors. Therefore inserts from plasmids pRAK297, pRAK316, pRAK317 and pRAK363 were inserted at the att site in the chromosome of ATM 809 using the $\lambda \ln C h$ tool as described by Boyd et al. [54]. Briefly, homology between the ksgA-pGEMT constructs (near-ori region and part of the bla gene) and sequences on the InCh bacteriophage allowed some phages to acquire both the ampicillin resistance gene (i.e. bla) and the vector ksgA insert by recombination. After subsequent infection of ATM809, the recombinant phage bla - ksgA region was transferred into the bacterial att site by site-specific recombination, creating lysogens. Finally recombination between the bacterial genome near att and the phage DNA that carry the same region resulted in deletion of the phage while leaving bla-ksgA in the bacterial genome, creating bacterial stable recombinants. Insertion sites were confirmed by PCR [54]. Primers Puc-F and Puc$\mathrm{R}[10]$ showed the presence of the $\mathrm{ksgA}$ insert in ATM810, ATM811, ATM812 and ATM815 (Table 1). Primers GalF [5'-CTTGCTGAGTACGTGAGTTC-3'] and IG-R [5'ACGTTGGAGTCCACGTTCTT-3'] amplified a 1248 bp product in ATM810, ATM811 and ATM815 only, showing that these three strains were stable recombinants. On the other hand, we were unable to obtain "stable" recombinants from ATM812, as seen by PCR amplification of a 977 bp product using primers GalF and Att-R [5'-AAGCAGGCTTCAACGGATTC-3'], similarily to MC4100 and ATM809. Maintenance of the ksgA insert in ATM812 chromosome was followed throughout the study by PCR with Puc-F and Puc-R and by the constant presence of ampicillin for selection.

\section{Analysis of bacterial growth}

The effect of KsgA on bacterial growth was first studied in E. coli recombinants. Cells were grown at $37^{\circ} \mathrm{C}$ overnight in LB without salt [55] supplemented with ampicillin. Saturated cultures were diluted $1 / 100$ in fresh expression medium (i.e. LB without salt supplemented with $1 \mathrm{mM}$ IPTG) and incubated at $37^{\circ} \mathrm{C}$ for 2 to 3 hours, then normalized to an $\mathrm{OD}_{600 \mathrm{~nm}}$ equivalent of 0.5 . Bacteria were serially diluted in sterile buffered saline gelatin $[150 \mathrm{mM}$ $\mathrm{NaCl}, 2 \mathrm{mM} \mathrm{KH}{ }_{2} \mathrm{PO}_{4}, 4 \mathrm{mM} \mathrm{Na}_{2} \mathrm{HPO}_{4}, 0.01 \%$ gelatin]. For each dilution, aliquots of $2 \mu \mathrm{l}$ were spotted onto two expression medium agar plates. One plate was left at $20^{\circ} \mathrm{C}$ for about $30 \mathrm{hrs}$ and the second plate was incubated at $30^{\circ} \mathrm{C}$ for $12 \mathrm{hrs}$ (Figure 4). $100 \mu \mathrm{l}$ of a $10^{-5}$ dilution was plated on expression medium agar plates and incubated at $37^{\circ} \mathrm{C}$ for $12 \mathrm{hrs}$. The sizes of 15 random colonies were determined for each strain and averaged.

The effect of KsgA on C. trachomatis growth was determined by measuring and averaging the size of a minimum of 60 plaques formed by the two C. trachomatis L2 variants in the absence of selection, two weeks after simultaneous inoculation onto three $60-\mathrm{mm}$ confluent monolayers of mouse fibroblast cells each.

\section{KSM sensitivity assays}

MIC was determined for E. coli in test tubes inoculated with about $10^{5}$ bacteria collected from exponential phase cultures grown at $37^{\circ} \mathrm{C}$ in expression medium containing various concentrations of KSM. MIC was defined as the lowest concentration at which no growth was visible after 
16 hrs incubation at $37^{\circ} \mathrm{C}$ (Table 1 ). Subsequently, cultures were also incubated in triplicate with agitation for 24 hrs in the presence of 50, 250,500, 750 and $1000 \mu \mathrm{g} \mathrm{ml}^{-1}$ of KSM in expression medium. Growth was determined spectrophotometrically at $600 \mathrm{~nm}$ and normalized to the value obtained for ATM809 at the same concentration of KSM. KSM inhibition growth curves (Figure 3) were generated using the Prism 3.0 software (GraphPad Software, Inc, San Diego, CA).

Susceptibility of C. trachomatis and C. psittaci to KSM was examined in the plaque assay. MIC was defined as the drug concentration that inhibits the development of $10^{5}$ chlamydial plaque-forming units (PFU) in a confluent L2 monolayer in a $60 \mathrm{~mm}$ dish [11]. To test for spontaneous drug resistance, $60 \mathrm{~mm}$ dishes were infected with $10^{7}$ to $10^{8}$ PFU (MOI 1 to 10 ) and the drug was added two hrs p.i. at a concentration high enough to inhibit the cytotoxicity associated with this inoculum size. The frequency of spontaneous mutation to drug resistance was determined by dividing the number of PFU on selective medium by the number of PFU added to the monolayer (as measured by titration of PFU in the absence of antibiotic) [11]. Three clonal C. trachomatis $\mathrm{KSM}^{\mathrm{r}}$ isolates, including L2 ksgAE9 (Table 1) were independently purified in the plaque assay in the presence of $300 \mu \mathrm{g} / \mathrm{ml}$ of KSM, following 7 to 13 successive passages in mouse cells in the presence of increasing concentrations of antibiotic (from 100 to $800 \mu \mathrm{g} \mathrm{ml}^{-1}$ ).

\section{PCR and DNA sequencing of the KSM resistance targets in Chlamydia}

PCR amplification and DNA sequencing were used to determine whether chlamydial resistance to KSM was due to a mutation in the $16 \mathrm{~S}$ rRNA gene as described in [13] or in $k s g A$ using the primers described above. Because $k s g A$ is apparently the second gene of a bicistronic operon in $C$. trachomatis and C. psittaci, we also sequenced about $2 \mathrm{~kb}$ upsteam of $k s g A$. DNA sequences for each antibiotic resistant isolate were aligned using Clone Manager 8 and compared to the respective DNA sequence obtained from the wild-type parental strain. We also amplified C. trachomatis L2 rpsI region using primers rpsI-F1 [5'-GCTGAGAAAGTGCGTTTGACTG-3'] and rpsI-R1 [5'-GAAAGCAAGCACGGGACAAATC-3'] and sequenced the PCR fragment using primer rpsI-F2 [5'-ACATGATTGCGCGAAAGC-3']. No mutation was seen in the three KSM resistant isolates.

\section{Nucleotide sequence accession number}

C. psittaci 6BC ksgA sequence determined in the present study has been deposited in GenBank under accession number GQ284731.

\section{Authors' contributions}

$\mathrm{RB}$ designed and conceived the study, conducted the experiments, analyzed results and wrote the manuscript. ATM analyzed results and revised the manuscript.

\section{Acknowledgements}

This work was supported by grant Al44033 from the National Institute of Allergy and Infectious Diseases.

Rachel Binet acknowledges Nancy E. Adams for cell culture assistance and Derek Fisher and Aishwarya V. Ramaswamy for critical reading of the manuscript.

\section{References}

I. Noller HF: RNA structure: reading the ribosome. Science 2005 , 309:|1508-15|4.

2. McCloskey JA, Rozenski J: The Small Subunit rRNA Modification Database. Nucleic Acids Res 2005, 33:DI35-DI38.

3. Cunningham PR, Weitzmann CJ, Nurse K, Masurel R, Van Knippenberg PH, Ofengand J: Site-specific mutation of the conserved m62 A m62 A residues of $E$. coli 165 ribosomal RNA. Effects on ribosome function and activity of the ksgA methyltransferase. Biochim Biophys Acta 1990, 1050: 18-26.

4. Park $\mathrm{AK}, \mathrm{Kim} \mathrm{H}, \mathrm{Jin} \mathrm{HJ}$ : Comprehensive phylogenetic analysis of evolutionarily conserved rRNA adenine dimethyltransferase suggests diverse bacterial contributions to the nucleusencoded plastid proteome. Mol Phylogenet Evol 2009, 50:282-289.

5. McCulloch V, Seidel-Rogol BL, Shadel GS: A human mitochondrial transcription factor is related to RNA adenine methyltransferases and binds S-adenosylmethionine. Mol Cell Biol 2002, 22: III6-II 25 .

6. Lafontaine D, Vandenhaute J, Tollervey D: The I8S rRNA dimethylase Dim I p is required for pre-ribosomal RNA processing in yeast. Genes Dev 1995, 9:2470-248I.

7. Corsaro D, Venditti D: Emerging chlamydial infections. Crit Rev Microbiol 2004, 30:75-106.

8. Corsaro D, Greub G: Pathogenic potential of novel Chlamydiae and diagnostic approaches to infections due to these obligate intracellular bacteria. Clin Microbiol Rev 2006, 19:283-297.

9. Abdelrahman YM, Belland RJ: The chlamydial developmental cycle. FEMS Microbiol Rev 2005, 29:949-959.

10. Binet R, Maurelli AT: Frequency of development and associated physiological cost of azithromycin resistance in Chlamydia psittaci 6BC and C. trachomatis L2. Antimicrob Agents Chemother 2007, 5 I :4267-4275.

II. Binet R, Maurelli AT: Frequency of spontaneous mutations that confer antibiotic resistance in Chlamydia spp. Antimicrob Agents Chemother 2005, 49:2865-2873.

12. Wernegreen JJ: For better or worse: genomic consequences of intracellular mutualism and parasitism. Curr Opin Genet Dev 2005, 15:572-583.

13. Binet R, Maurelli AT: Transformation and isolation of allelic exchange mutants of Chlamydia psittaci using recombinant DNA introduced by electroporation. Proc Natl Acad Sci USA 2009, 106:292-297.

14. Griffiths E, Ventresca MS, Gupta RS: BLAST screening of chlamydial genomes to identify signature proteins that are unique for the Chlamydiales, Chlamydiaceae, Chlamydophila and Chlamydia groups of species. BMC Genomics 2006, 7:14.

15. Belland RJ, Zhong G, Crane DD, Hogan D, Sturdevant D, Sharma J, Beatty WL, Caldwell HD: Genomic transcriptional profiling of the developmental cycle of Chlamydia trachomatis. Proc Natl Acad Sci USA 2003, 100:8478-8483.

16. Ma J, Campbell A, Karlin S: Correlations between Shine-Dalgarno sequences and gene features such as predicted expression levels and operon structures. J Bacteriol 2002, 1 84:5733-5745.

17. Dereeper A, Guignon V, Blanc G, Audic S, Buffet S, Chevenet F, Dufayard JF, Guindon S, Lefort V, Lescot M, Claverie JM, Gascuel O: Phylogeny.fr: robust phylogenetic analysis for the non-specialist. Nucleic Acids Res 2008, 36:W465-W469. 
18. Everett KD, Bush RM, Andersen AA: Emended description of the order Chlamydiales, proposal of Parachlamydiaceae fam. nov. and Simkaniaceae fam. nov., each containing one monotypic genus, revised taxonomy of the family Chlamydiaceae, including a new genus and five new species, and standards for the identification of organisms. Int J Syst Bacteriol 1999, 49(Pt 2):4I5-440.

19. Pannekoek Y, Morelli G, Kusecek B, Morré SA, Ossewaarde JM, Langerak $A A$, Ende $A$ van der: Multi locus sequence typing of Chlamydiales: clonal groupings within the obligate intracellular bacteria Chlamydia trachomatis. BMC Microbiol 2008, 8:42.

20. Moustafa A, Reyes-Prieto A, Bhattacharya D: Chlamydiae has contributed at least 55 genes to Plantae with predominantly plastid functions. PLOS ONE 2008, 3:e2205.

21. Brinkman FS, Blanchard JL, Cherkasov A, Av-Gay Y, Brunham RC, Fernandez RC, Finlay BB, Otto SP, Ouellette BF, Keeling PJ, Rose AM, Hancock RE, Jones SJ, Greberg H: Evidence that plant-like genes in Chlamydia species reflect an ancestral relationship between Chlamydiaceae, cyanobacteria, and the chloroplast. Genome Res 2002, I 2: I I59- I I67.

22. Horn M, Collingro A, Schmitz-Esser S, Beier CL, Purkhold U, Fartmann B, Brandt P, Nyakatura G], Droege M, Frishman D, Rattei T, Mewes HW, Wagner $M$ : Illuminating the evolutionary history of chlamydiae. Science 2004, 304:728-730.

23. McCoy AJ, Adams NE, Hudson AO, Gilvarg C, Leustek T, Maurelli AT: L,L-diaminopimelate aminotransferase, a trans-kingdom enzyme shared by Chlamydia and plants for synthesis of diaminopimelate/lysine. Proc Natl Acad Sci USA 2006, I 03:|7909-|79|4.

24. Cotney J, Shadel GS: Evidence for an early gene duplication event in the evolution of the mitochondrial transcription factor B family and maintenance of rRNA methyltransferase activity in human mtTFBI and mtTFB2. J Mol Evol 2006, 63:707-7I7.

25. O'Farrell HC, Pulicherla N, Desai PM, Rife JP: Recognition of a complex substrate by the KsgA/Dim I family of enzymes has been conserved throughout evolution. RNA 2006, I 2:725-733.

26. Housen I, Demonte D, Lafontaine D, Vandenhaute J: Cloning and characterization of the KIDIMI gene from Kluyveromyces lactis encoding the m2(6)A dimethylase of the I8S rRNA. Yeast 1997, | 3:777-78|.

27. Lafontaine D, Delcour J, Glasser AL, Desgres J, Vandenhaute J: The DIMI gene responsible for the conserved m6(2)Am6(2)A dimethylation in the 3'-terminal loop of 18 S rRNA is essential in yeast. I Mol Biol 1994, 241:492-497.

28. Helser TL, Davies JE, Dahlberg JE: Mechanism of kasugamycin resistance in Escherichia coli. Nat New Biol 1972, 235:6-9.

29. Datsenko KA, Wanner BL: One-step inactivation of chromosomal genes in Escherichia coli K-I 2 using PCR products. Proc Natl Acad Sci USA 2000, 97:6640-6645.

30. Seidel-Rogol BL, McCulloch V, Shadel GS: Human mitochondrial transcription factor $B I$ methylates ribosomal RNA at a conserved stem-loop. Nat Genet 2003, 33:23-24.

31. Demirci H, Belardinelli R, Seri E, Gregory ST, Gualerzi C, Dahlberg $A E$, Jogl G: Structural rearrangements in the active site of the Thermus thermophilus I6S rRNA methyltransferase KsgA in a binary complex with 5'-methylthioadenosine. J Mol Biol 2009, 388:27I-282.

32. Connolly K, Rife JP, Culver G: Mechanistic insight into the ribosome biogenesis functions of the ancient protein KsgA. Mol Microbiol 2008, 70:1062-1075.

33. Tokuhisa JG, Vijayan P, Feldmann KA, Browse JA: Chloroplast development at low temperatures requires a homolog of DIMI, a yeast gene encoding the I8S rRNA dimethylase. Plant Cell I998, 10:699-7II.

34. Rife JP, Moore PB: The structure of a methylated tetraloop in I 6S ribosomal RNA. Structure 1998, 6:747-756.

35. Guymon R, Pomerantz SC, Ison JN, Crain PF, McCloskey JA: Posttranscriptional modifications in the small subunit ribosomal RNA from Thermotoga maritima, including presence of a novel modified cytidine. RNA 2007, I 3:396-403.

36. Guymon R, Pomerantz SC, Crain PF, McCloskey JA: Influence of phylogeny on posttranscriptional modification of rRNA in thermophilic prokaryotes: the complete modification map of I6S rRNA of Thermus thermophilus. Biochemistry 2006, 45:4888-4899.
37. Seiga K, Iwata M: Clinical application of Kasugamycin for Pseudomonas aeruginosa infections. J Antibiot [B] 1967, 20:184-I86.

38. Vila-Sanjurjo A, Squires CL, Dahlberg AE: Isolation of kasugamycin resistant mutants in the $16 \mathrm{~S}$ ribosomal RNA of Escherichia coli. J Mol Biol 1999, 293:I-8

39. Schuwirth BS, Day JM, Hau CW, Janssen GR, Dahlberg AE, Cate JH, Vila-Sanjurjo A: Structural analysis of kasugamycin inhibition of translation. Nat Struct Mol Biol 2006, I 3:879-886.

40. Schluenzen F, Takemoto C, Wilson DN, Kaminishi T, Harms JM, Hanawa-Suetsugu K, Szaflarski W, Kawazoe M, Shirouzu M, Nierhaus $\mathrm{KH}$, Yokoyama S, Fucini P: The antibiotic kasugamycin mimics mRNA nucleotides to destabilize tRNA binding and inhibit canonical translation initiation. Nat Struct Mol Biol 2006 | 3:87|-878.

4I. Woodcock J, Moazed D, Cannon M, Davies J, Noller HF: Interaction of antibiotics with A- and P-site-specific bases in I6S ribosomal RNA. EMBO J 1991, 10:3099-3103.

42. Xu Z, O'Farrell HC, Rife JP, Culver GM: A conserved rRNA methyltransferase regulates ribosome biogenesis. Nat Struct Mol Biol 2008, 15:534-536.

43. Duffin PM, Seifert HS: ksgA mutations confer resistance to kasugamycin in Neisseria gonorrhoeae. Int J Antimicrob Agents 2008 , 33(4):321-7.

44. Ochi K, Kim JY, Tanaka Y, Wang G, Masuda K, Nanamiya H, Okamoto S, Tokuyama S, Adachi Y, Kawamura F: Inactivation of KsgA, a I 6S rRNA methyltransferase, causes vigorous emergence of mutants with high-level kasugamycin resistance. Antimicrob Agents Chemother 2009, 53:193-201.

45. Asai T, Zaporojets D, Squires C, Squires CL: An Escherichia coli strain with all chromosomal rRNA operons inactivated: complete exchange of rRNA genes between bacteria. Proc Natl Acad Sci USA 1999, 96: | 97|-1976.

46. Dabbs ER: Escherichia coli kasugamycin dependence arising from mutation at the rpsl locus. I Bacteriol 1983, 153:709-7I 5.

47. Bichara M, Wagner J, Lambert IB: Mechanisms of tandem repeat instability in bacteria. Mutat Res 2006, 598: |44-163.

48. Binet R, Maurelli AT: Fitness cost due to mutations in the I6S rRNA associated with spectinomycin resistance in Chlamydia psittaci 6BC. Antimicrob Agents Chemother 2005, 49:4455-4464.

49. O'Farrell HC, Scarsdale JN, Rife JP: Crystal structure of KsgA, a universally conserved rRNA adenine dimethyltransferase in Escherichia coli. I Mol Biol 2004, 339:337-353.

50. Tufariello JM, Mi K, Xu J, Manabe YC, Kesavan AK, Drumm J, Tanaka K, Jacobs WR Jr, Chan J: Deletion of the Mycobacterium tuberculosis resuscitation-promoting factor Rv 1009 gene results in delayed reactivation from chronic tuberculosis. Infect Immun 2006, 74:2985-2995.

5I. Mecsas J, Bilis I, Falkow S: Identification of attenuated Yersinia pseudotuberculosis strains and characterization of an orogastric infection in BALB/c mice on day 5 postinfection by signature-tagged mutagenesis. Infect Immun 200I, 69:2779-2787.

52. Alvesalo JK, Siiskonen A, Vainio MJ, Tammela PS, Vuorela PM: Similarity based virtual screening: a tool for targeted library design. J Med Chem 2006, 49:2353-2356.

53. Pannekoek Y, Heurgue-Hamard V, Langerak AA, Speijer D, Buckingham $\mathrm{RH}$, van der EA: The N5-glutamine S-adenosyl-L-methionine-dependent methyltransferase PrmC/HemK in Chlamydia trachomatis methylates class I release factors. Bacteriol 2005, | 87:507-5 I I.

54. Boyd D, Weiss DS, Chen JC, Beckwith J: Towards single-copy gene expression systems making gene cloning physiologically relevant: lambda InCh, a simple Escherichia coli plasmid-chromosome shuttle system. J Bacteriol 2000, I 82:842-847.

55. Campbell BD, Kadner RJ: Relation of aerobiosis and ionic strength to the uptake of dihydrostreptomycin in Escherichia coli. Biochim Biophys Acta 1980, 593: I- I0.

56. Hanahan D: Studies on transformation of Escherichia coli with plasmids. J Mol Biol 1983, I 66:557-580.

57. Casadaban MJ, Cohen SN: Lactose genes fused to exogenous promoters in one step using a Mu-lac bacteriophage: in vivo probe for transcriptional control sequences. Proc Natl Acad Sci USA 1979, 76:4530-4533. 